\title{
SURFACE TOPOGRAPHY ANALYSIS OF PRECISION ASSEMBLIES OF FUEL INJECTOR NOZZLES
}

\author{
Andrzej Miszczak, Wojciech Labuda, Maciej Grondecki \\ Gdynia Maritime University, Faculty of Marine Engineering \\ Morska Street 81-87, 81-225 Gdynia, Poland \\ tel.: +48 58 6901348, fax: +48586901399 \\ e-mail:miszczak@wm.am.gdynia.pl,wlabuda@am.gdynia.pl,mgrondecki@gmail.com
}

\begin{abstract}
Precision surface assemblies can be found in the two locations in a fuel system of a diesel engine. These parts are the pumping section in an injection pump and the injector nozzles.

In this paper the authors present the results of surface topography measurements of precise surface assemblies of some fuel injectors. The measurements have been made with the atomic force microscope (AFM) NT-206. The results of surface topography measurements were presented in the form of $2 D$ and $3 D$ images and also as surface roughness profiles in some selected cross-sections of the investigated surfaces. It has been also shown cumulative roughness height distribution and roughness height distribution as well as Minkowski volume (first Minkowski functional).

After scanning the surface on the atomic force microscope, the obtained data were processed with the SurfaceXplorer ${ }^{\circledR} 1.311$ and Gwyddion 2.35 software.

The study concerned some new injector nozzles and also injector nozzles after a certain time of operation. The side and the conical precise surface assembly of the injector nozzle body and needle were tested.

The atomic force microscope NT-206 allows to perform a surface scan of the sample with maximum dimensions of $32 \times 32 \mu \mathrm{m}$ and a maximum height of roughness $\pm 1 \mu \mathrm{m}$. Scanned area was divided into $256 \times 256$ measurement points, while the measurement was carried out in a static (contact) mode. The results presented in this paper also includes the calculated values of $\mathrm{Ra}, \mathrm{Sa}$ (roughness average) and $\mathrm{Rq}, \mathrm{Sq}$ (root mean square roughness) surface roughness parameters and the value of the skewness Ssk (Rsk), kurtosis Sku (Rku) and maximum distance between the lowest valley and the highest peak of investigated surface - Rt.

The obtained data allow evaluating the degree and type of wear of tested surfaces on the micro-scale.
\end{abstract}

Keywords: Atomic Force Microscope, surface topography, roughness, plunger, barrel, injector pump pumping section

\section{Introduction}

The surface structure influences strong on process of wear as well as on the process of cooperation of these surfaces. This is of particular importance in the case of the surfaces of precision assemblies, in which the average gap between the cooperating surfaces is approximately 1-3 $\mu \mathrm{m}$ and whereas the lubricant is used a liquid with a low viscosity value (fuel) [5]. This study concerns analysis of the surface structure of precision assemblies of the fuel system of a diesel engine. The surfaces of precision assemblies can be found in the two locations in fuel system. Firstly - in the pumping section of the injection pump, secondly, they are surfaces of injectors. In this paper, the authors analyse the topography of the surfaces of the needle and the body of new as well as used injector nozzle.

The elements of the injector nozzle are individually adjusted so that the gap between the side surface of the plunger and the inner surface of the barrel is approximately 1-3 $\mu \mathrm{m}$ [5]. This clearance provides sufficient lubrication of the side surfaces of the plunger and the barrel while still providing enough sealing to maintain high pressure of diesel fuel which is necessary to achieve proper fuel injection. The quality of the surfaces of precision assemblies of the injection pump thus has a very large impact on the correct operation of the entire diesel engine. The situation is complicated by the continuous process of wear resulting from the existence of hard impurities in the fuel. Impurities in the fuel are of the same order of magnitude or greater, as the 
gap of the needle and the body of injector sprayer (from tenths of microns to several microns) [5]. The penetration of the hard particles from the fuel, between the side surface of the needle and body, can cause scratching (indentation) of such precision assemblies, which generates leakage and pressure drop of injection process. The particles of larger sizes can cause even the suspension of the needle resulting in a lack of spontaneous combustion in the cylinder. Additionally the impurity particles may be squashed and after that deposit on the conical part of the needle or the body (see Fig. 1) causing a leak. All of these failures may result in reduced fuel dose, deterioration of spraying quality or even a lack of fuel injection, increased fuel consumption, penetration of fuel into the lubricating oil and deterioration of its performance characteristics.

Detail - A

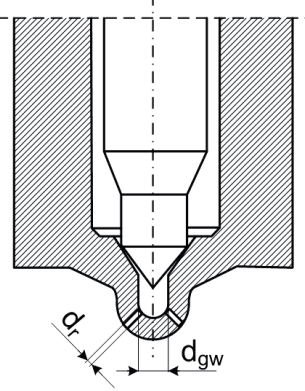

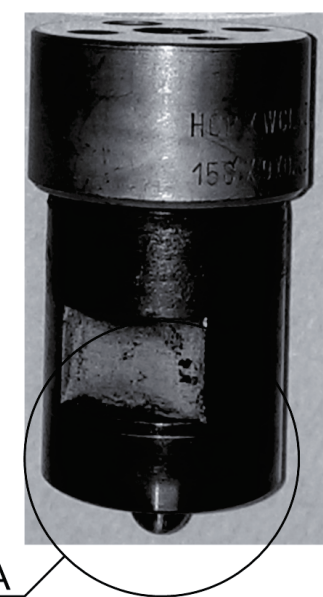

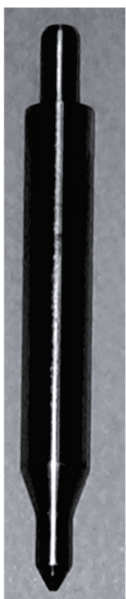

Fig. 1. View of the body and needle of the injector nozzle HCP/WCLVZx A25/30-350-27-440-00 158x9x0,320

The aim of this work is to investigate the surface topography of the new and used precision assemblies of injector nozzle (Fig. 2) operating in Cegielski-Sulzer 3AL25/30 engine and the evaluation of the wear of the these surfaces.

The determination of wear of the surfaces may be made, inter alia, on the basis of several basic parameters of the surface structure [1-11]. In modern studies, these parameters relate to both profiles (2D) and surfaces (3D), too [2, 3, 8-11]. In this study, the surface parameters were determined in accordance with the PN-EN ISO 4287/1999 standard. These parameters are roughness average $\mathrm{Sa}(\mathrm{Ra})$, root mean square roughness $\mathrm{Sq}(\mathrm{Rq})$, skewness Ssk (Rsk), kurtosis $\mathrm{Sku}(\mathrm{Rku})$, total height of roughness $\mathrm{St}(\mathrm{Rt})$.
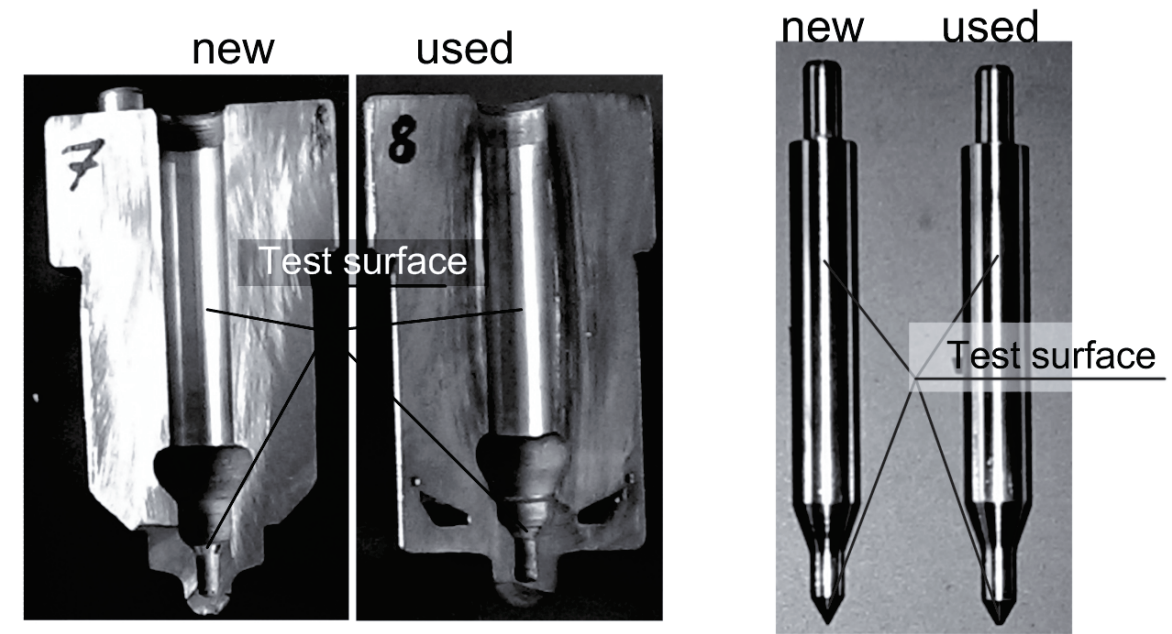

Fig. 2. The brand new and used one injector sprayer of 3AL25/30 engine; a) view of sectioned bodies, b) view of needles 


\section{Investigations of surface structure}

The study of surface topography was carried for the new and the used injector nozzles, which was operating in Cegielski-Sulzer 3AL25/30 engine. It has been studied the injector nozzles of $\mathrm{H}$. Cegielski - Poznań S.A. company, with catalogue number HCP/WCLVZ A25/30-350-27-440-00 $158 \times 9 \times 0.320$.

The measurement of the surface structure at micro-scale has been made with the Atomic Force Microscope (AFM) NT-206. This microscope can measure the area with dimensions of $32 \mu \mathrm{m} \mathrm{x}$ $32 \mu \mathrm{m}$, while the maximum measurable roughness height is $\pm 1 \mu \mathrm{m}$ [1]. The scanned area was divided into $256 \times 256$ measurement points. The measurements were carried out in the static (contact) mode.

The samples that can be measured on the microscope are limited in overall dimensions. The maximum height is $8 \mathrm{~mm}$ while the width and length of the sample is about $1 \mathrm{~cm}$.

Then, a dozen surface scans of each sample were carried out, among which, it has been selected and presented to the three images and the side surface of the needle and the body in the form of a 2D view (Fig. 3, 5, 7, 9) and one of the selected surface in 3D also the selected crosssectional profile as well as first Minkowski functional $M F(z)$, height distribution and cumulative height distribution (Fig. 4, 6, 8, 10).

The first Minkowski functional is defined as [8]:

$$
M F(z)=\frac{N_{B}}{N_{B}+N_{W}},
$$

where:

$N_{B}$ - the so-called black pixels (the space filled by material medium on the level $z$ of considered section of roughness surface),

$N_{W}$ - the so-called white pixels (the space filled by air medium on the level $z$ of considered section of roughness surface).

The first Minkowski functional measures the relative matter amount existing underneath the level $z$. The plot of the first functional in terms of level $z$ is the bearing area curve or AbbottFirestone curve [8].

After surface scanning on the atomic force microscopy, data was calculated in the SurfaceXplorer ${ }^{\circledR} 1.311$ or Gwyddion 2.35 software. Images of 2D, 3D, surface roughness profiles as well as cumulative roughness height distribution, roughness height distribution, first Minkowski functional have been generated in the Gwyddion 2.35.

Figure 3 shows a 2D view, as in Fig. 4 is shown a 3D view and cross-sectional profile of the needle of brand new injector nozzle surface. Additional, Fig. 4 contains graphs showing the Minkowski functional $\mathrm{MF}(\mathrm{z})$, roughness height distribution, cumulative roughness height distribution and also the data concerning the roughness parameters. The measured surface of body of the brand new injector nozzle, is shown in Fig. 5 and 6 in the same manner.
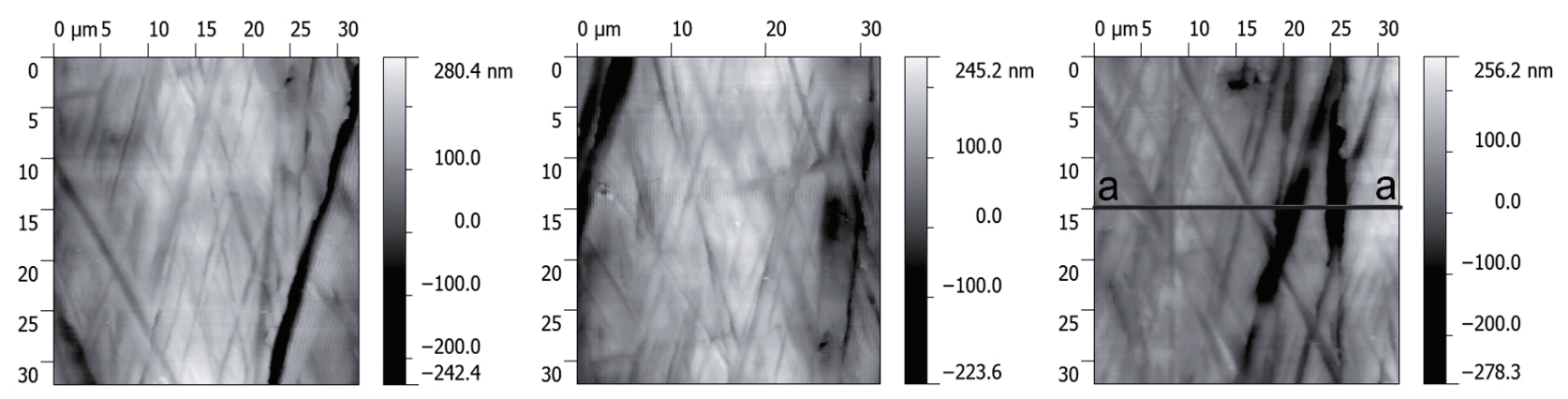

Fig. 3. $2 D$ view of surface of brand new needle of injector nozzle 
Figure 7 shows a 2D view, as in Fig. 8 is shown a 3D view and cross-sectional profile of the needle surface of the operated injector nozzle. As in the previous figures, there are also graphs showing Minkowski functional MF(z), the roughness height distribution and cumulative height distribution and the roughness parameters (Fig. 8). In the same manner, in Fig. 9 and 10, are shown the results for the surface of used body of injector nozzle.
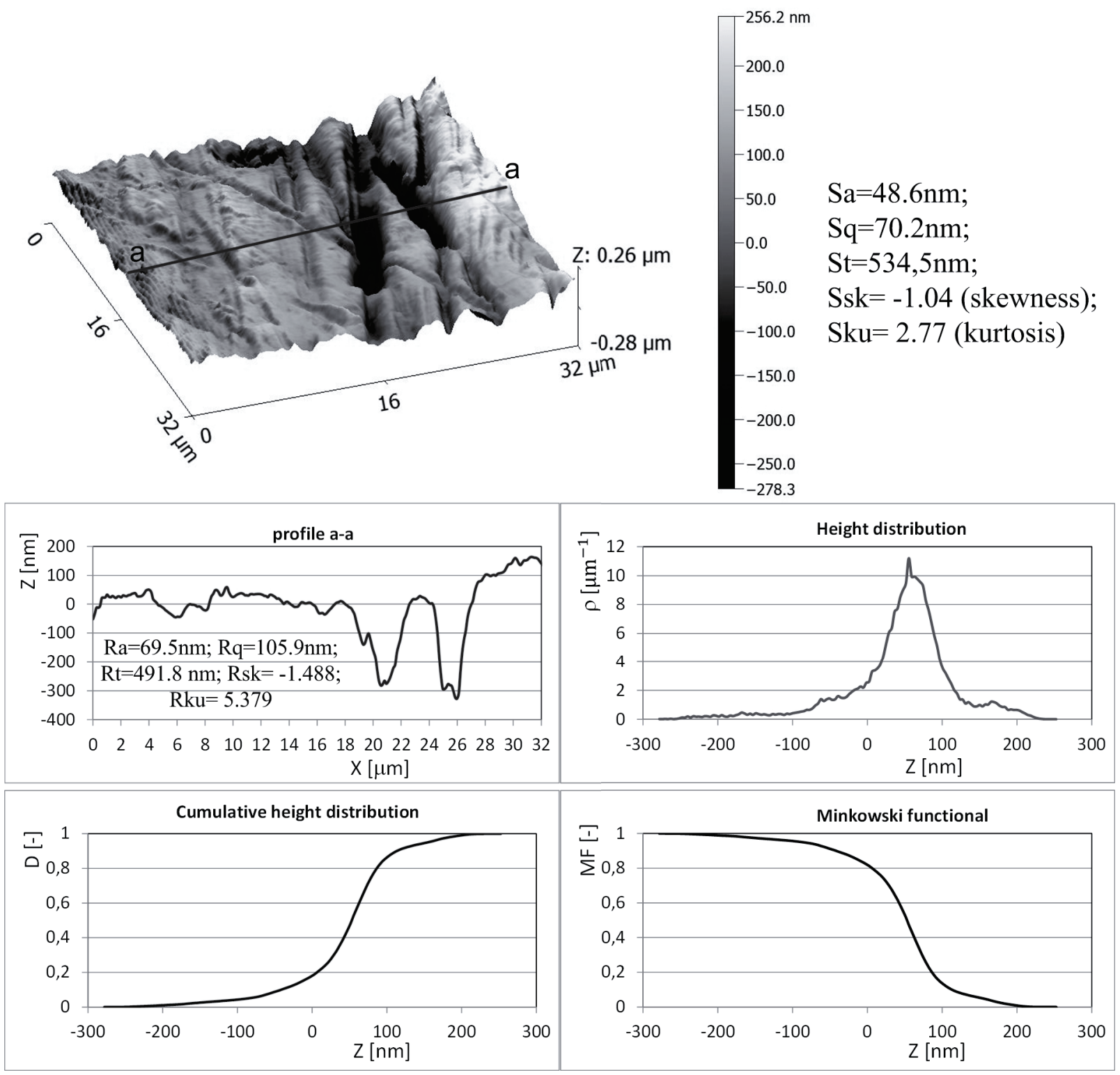

Fig. 4. The surface topography of needle of brand new injector nozzle; a) 3D-view, b) profile of the selected crosssection, c) Minkowski functional, d) cumulative height distribution, e) height distribution
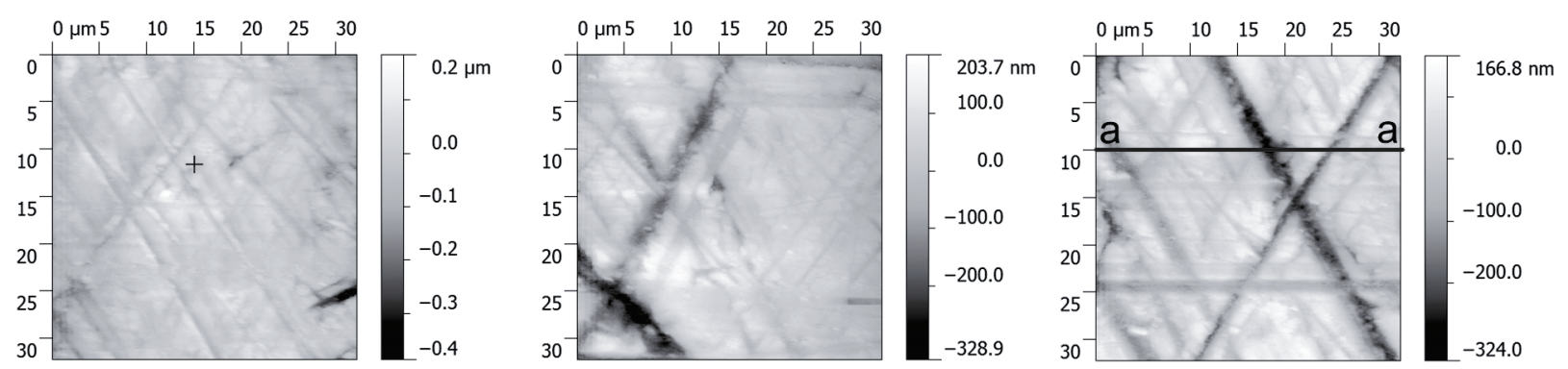

Fig. 5. 2D-view of the inner surface of the body of brand new injector nozzle 
The other one of important surfaces of precision assemblies of injector nozzle are conical surfaces of needle and body. These surfaces are individually lapped so they are the kind of valve, which can tightly sealed outlet hole. This outlet hole is ended by one or more small holes atomizing fuel. 2D image as well as a selected cross-sectional profile of the conical surfaces of needle and the of the body are shown in Fig. 11 both for brand new and used sprayed injectors.

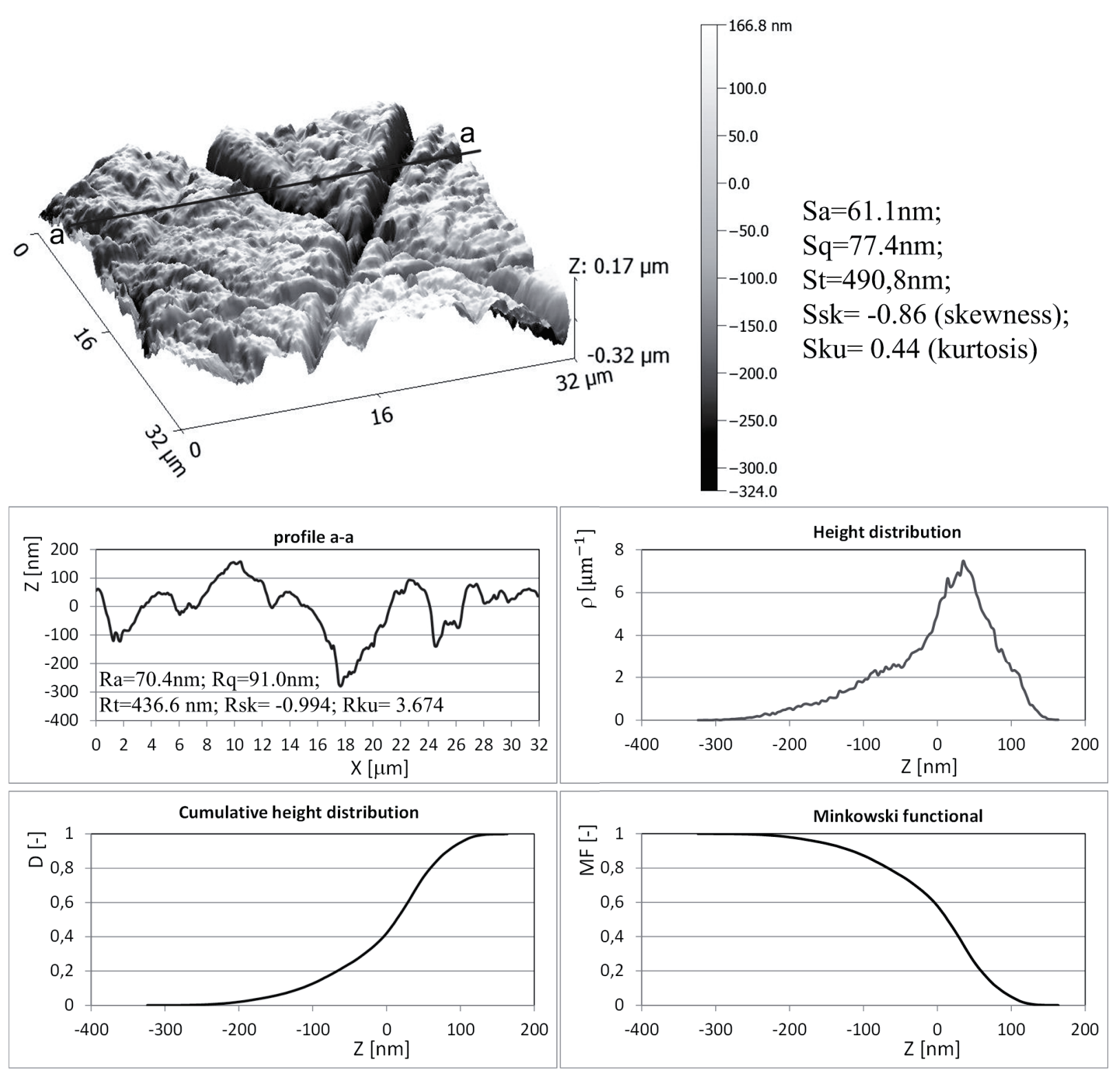

Fig. 6. The inner surface topography of the body of brand new injector nozzle; a) 3D view, b) profile of the selected cross-section, c) Minkowski functional, d) cumulative height distribution, e) height distribution
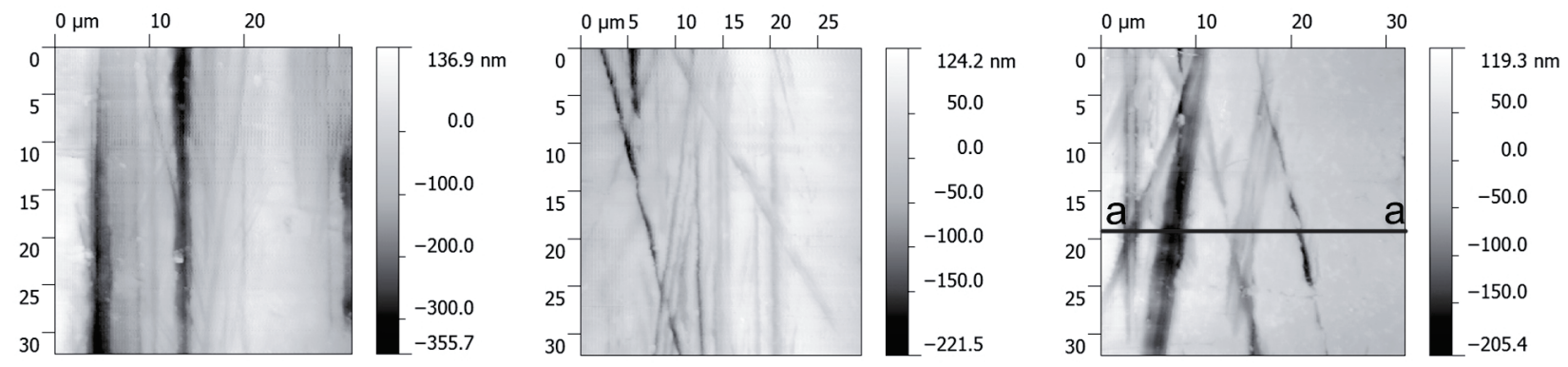

Fig. 7. 2D view of surface of the needle of operated injector nozzle 

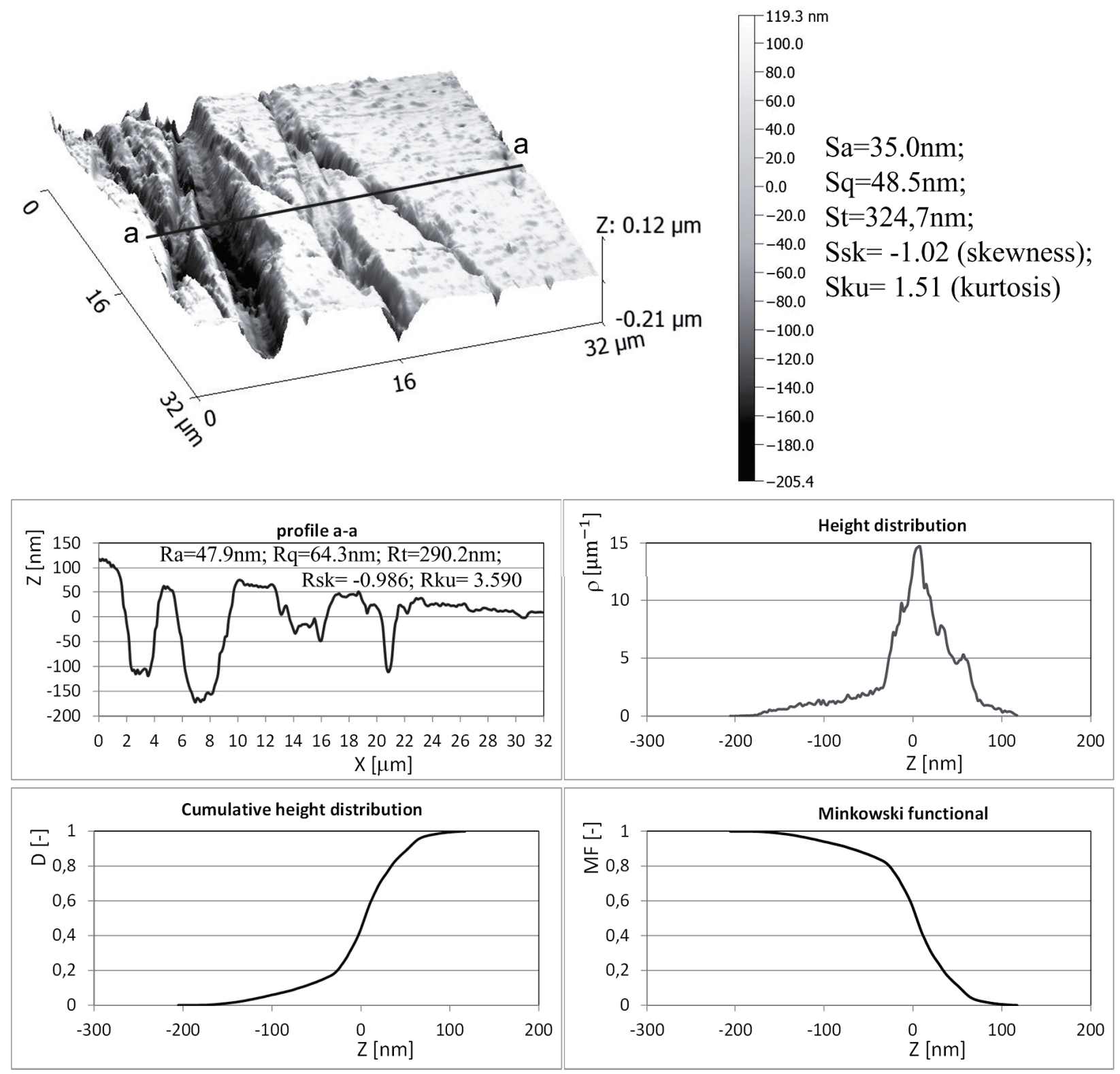

Fig. 8. The surface topography of needle of operated injector nozzle; a) 3D-view, b) profile of the selected crosssection, c) Minkowski functional, d) cumulative height distribution, e) height distribution
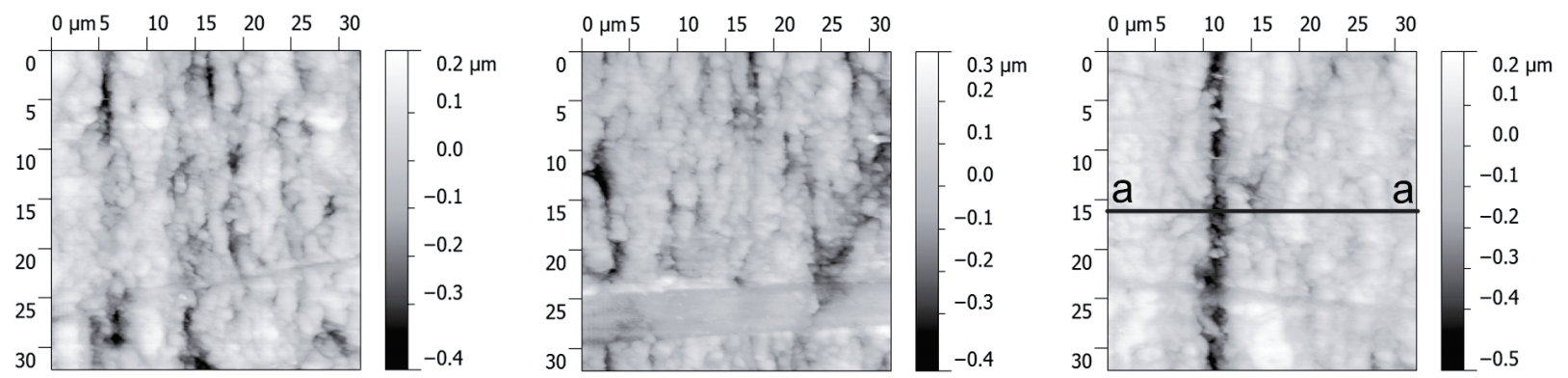

Fig. 9. 2D view of surface of the inner body of operated injector nozzle

The values of roughness parameters $\mathrm{Sa}$ and $\mathrm{Sq}(\mathrm{Ra}$ and $\mathrm{Rq}$ for profile) for the investigated needle and body surfaces of non-used injector nozzle, are in the range from $48 \mathrm{~nm}$ to $105 \mathrm{~nm}$ (Fig. 4 and 6), while these parameters for the investigated used needle and body of injector nozzle are in the range from $35 \mathrm{~nm}$ to $113 \mathrm{~nm}$ (Fig. 8 and 10). 


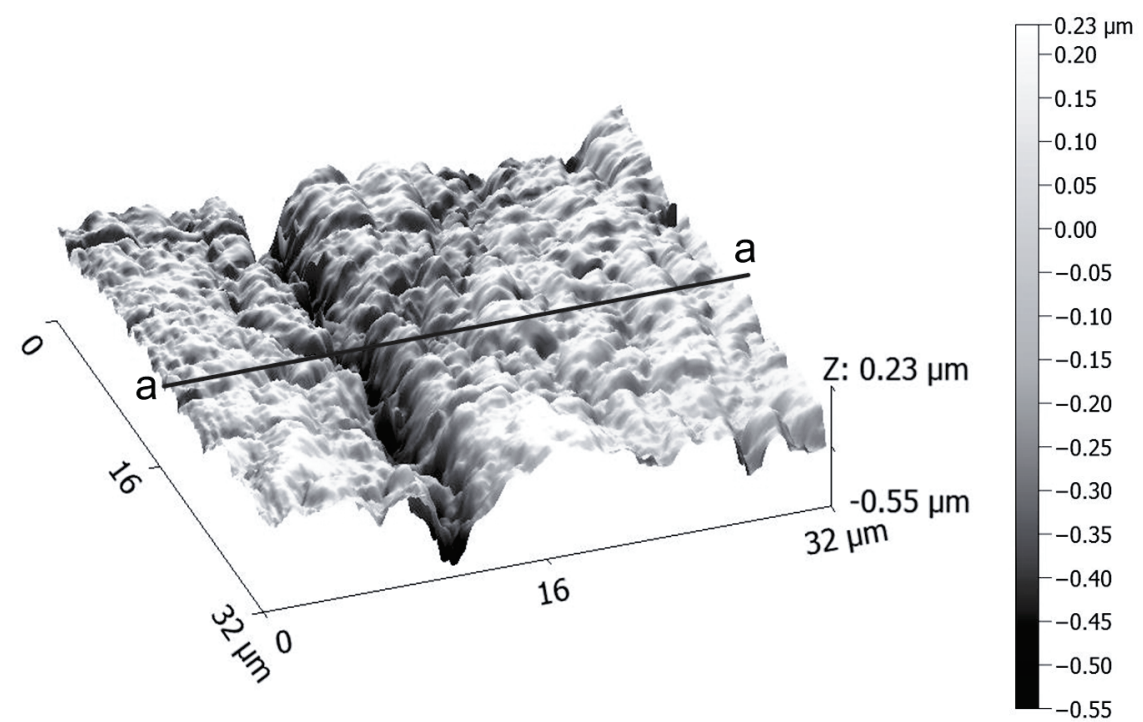

$\mathrm{Sa}=79.5 \mathrm{~nm}$

$\mathrm{Sq}=111.8 \mathrm{~nm}$;

$\mathrm{St}=783,8 \mathrm{~nm}$;

Ssk $=-1.51$ (skewness);

$\mathrm{Sku}=2.99$ (kurtosis)
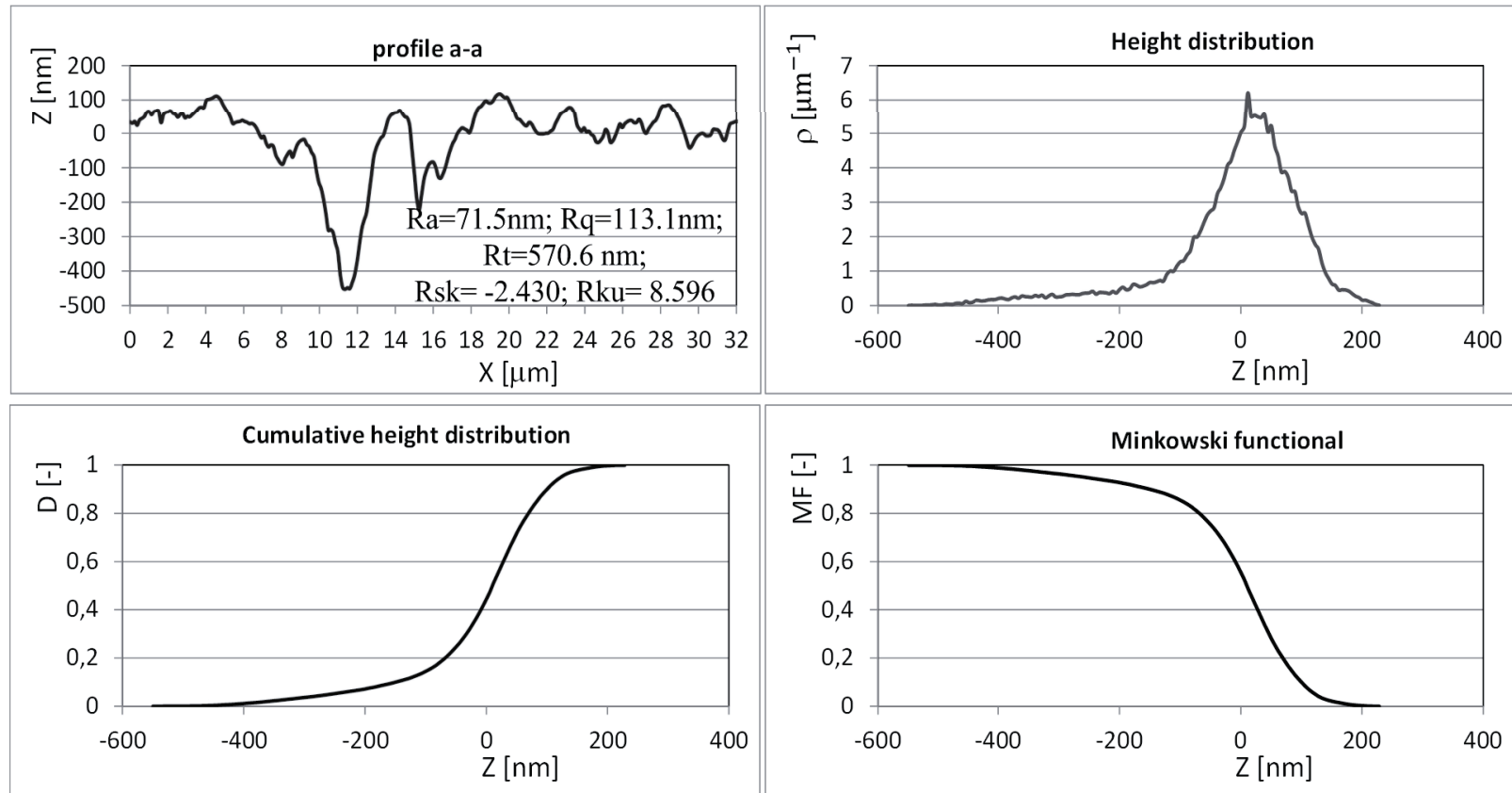

Fig. 10. The inner surface topography of body of operated injector nozzle; a) 3D-view, b) profile of the selected crosssection, c) Minkowski functional, d) cumulative height distribution, e) height distribution

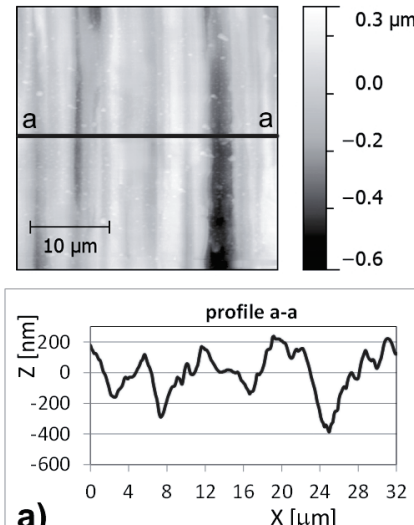

a)
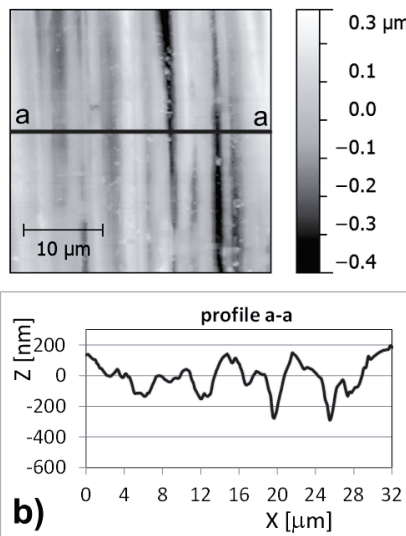
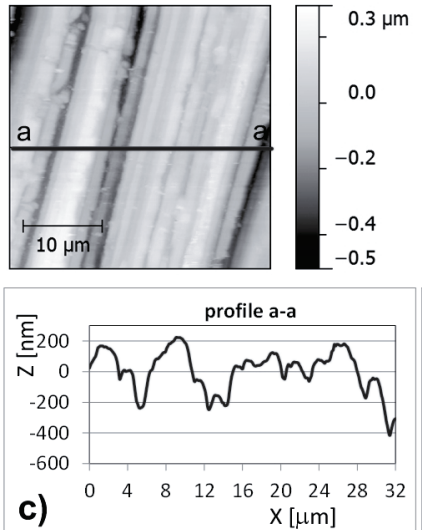
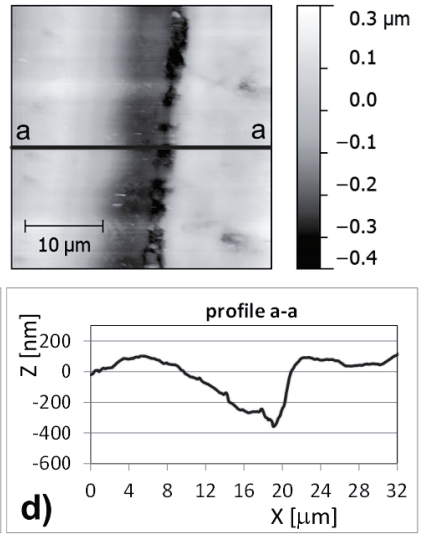

Fig. 11. 2D view and profile of the selected cross-sections of injector nozzle: a) conical surface of needle of the nonoperated injector nozzle, b) conical surface of needle of the operated injector nozzle, c) conical surface of body of the operated injector nozzle, d) conical surface of body of the operated injector nozzle 
The tested surfaces, especially the new ones, are characterized by the distinct traces of treatment. The surfaces of the used needle and body have blunted tops of roughness elements and deeper randomly distributed scratches (grooves), resulting from contact with hard contaminants from the fuel. The width of these impurities is of the order 2-4 $\mu \mathrm{m}$ (see Fig. 8 and 10) and their depth reaches $200-400 \mathrm{~nm}$.

The conical surfaces of the needle and the body of both new and used are characterized by regular and parallel grooves and hills. They arise from the process of lapping and cooperation of these surfaces. The total height of the profile is for brand new needle $\mathrm{Rt}=624.9 \mathrm{~nm}$, for operated needle $\mathrm{Rt}=484.0 \mathrm{~nm}$, for brand new body $\mathrm{Rt}=641.2$, for operated body $\mathrm{Rt}=474.7$.

\section{Observations and conclusions}

In this paper, are shown only selected surface topographies from among dozens of scans performed and analysed with the Atomic Force Microscope.

From the comparison of surface topography of the needle and body of the new and the used injector nozzle presented in this paper, it is evident that the surfaces of the used section are characterized by deep scratches and surface defects for similar values of $\mathrm{Ra}$ and $\mathrm{Rq}$ parameters. The width of scratches is of the order 1-3 $\mu \mathrm{m}$, i.e. the same order as the gap height of plungerbarrel-assembly, which means, that these scratches could have done the hard particles of impurities present in the fuel. Some scratches on the surfaces of new and used sprayed injector are due to the method of surface treatment (grinding, honing). In Fig. 3, 5, 7 are visible scratches crossing at an angle of approximately $30-35^{\circ}$ on the surfaces of the needles and $65^{\circ}$ on the surface of the body.

The precise analysis of the surface structure allows determining the degree and type of wear.

\section{References}

[1] Atomic Force Microscope NT-206 Operating Manual, A. V. Lykov Institute of Heat and Mass Transfer, Minsk 2010.

[2] Bharat Bhushan, Modern Tribology Handbook, CRC Press, London-New York-Washington, D.C. 2001.

[3] Dong-Hyeok Lee, Nahm-Gyoo Cho, Assessment of surface profile data acquired by a stylus profilometer, Measurement Science and Technology, Vol. 23, No. 10, 105601, doi:10.1088/ 0957-0233/23/10/105601, 12 p., 2012.

[4] Górecka, R., Polański, Z., Metrologia warstw wierzchniej, WNT, Warszawa 1983.

[5] Krępeć, T., Falkowski, H., Obsługa i naprawa aparatury paliwowej silników wysokoprężnych, Wydawnictwa Komunikacji i Łączności, Warszawa 1973.

[6] Matuszewski, M., Kierunkowość struktury geometrycznej powierzchni w transformacji warstwy wierzchniej, Rozprawa doktorska, Bydgoszcz 2013.

[7] Oczoś, K., Liubimov, V., Rozważania nad istotnościa parametrów struktury geometrycznej powierzchni w układzie 3D, Mechanik, R. 81, Nr 3, s. 129-130, 2008.

[8] Rodríguez-Valverde, M. A., Ramón-Torregrosa, P. J., Cabrerizo-Vílchez, M. A., Estimation of percolation threshold of acid-etched titanium surfaces using Minkowski functionals, Microscopy: Science, Technology, Applications and Education (Microscopy Book Series), Ed. A. Méndez-Vilas, J. Díaz. Formatex Research Center, Vol. 3, No. 4, pp. 1978-1983, 2010.

[9] Tomasik, J., Badania porównawcze parametrów mikrogeometrii powierzchni w układzie 2D i 3D, Mechanik, R. 82, Nr 8-9, s. 722-724, 2003.

[10] Whitehouse, D. J., Handbook of Surface and Nanometrology, University of Warwick, Institute of Physics Publishing, Bristol and Philadephia 2003.

[11] www.olympus-ims.com/en/knowledge/metrology/roughness/3d_parameter/, 2014. 